\title{
Práticas de gestantes soropositivas para HIV sobre o autocuidado: Construção de Tecnologia Educacional em Saúde
}

\author{
Practices of HIV seropositive pregnant women on self-care: construction of educational \\ health technology
}

Prácticas de mujeres embarazadas seropositivas VIH seropositivas sobre el autocuidado: construcción de tecnologia de salud educativa

Jeane Rodrigues Miranda Serrão ${ }^{1 *}$, Ivonete Vieira Pereira Peixoto ${ }^{1}$, Camilla Cristina Lisboa do Nascimento ${ }^{1}$, Analu Miranda Serrão ${ }^{1}$, Monica Custodia Abreu Pamplona ${ }^{1}$.

\section{RESUMO}

Objetivo: Construir uma tecnologia educacional em saúde para gestantes soropositivas para HIV. Métodos: Estudo descritivo, de natureza qualitativa, do tipo pesquisa participante. Participaram do grupo focal 10 gestantes com HIV. Após a dinâmica do grupo focal, foram analisados os depoimentos das mesmas e construído uma tecnologia educacional contendo os principais questionamentos das participantes e respostas com referencias de estudos realizados pelo Ministério da Saúde. Resultados: Com a metodologia realizada, foi possível construir como produto um vídeo educativo denominado "A gravidez em mulheres com HIV: vamos falar sobre?". Sobre os questionamentos delas, foi possível destacar que elas não sabiam como realizar o autocuidado de forma correta e que apresentam medo perante o estigma contido na doença. Conclusão: A elaboração de ferramentas educacionais se apresenta como forma de sanear dúvidas e apresenta-se como forma de aumento de vínculo entre o profissional e a usuária.

Palavras-chave: Gestantes, Autocuidado, Educação.

\begin{abstract}
Objective: To construct an educational health technology for HIV seropositive pregnant women. Methods: Descriptive study, of a qualitative nature, of the participant research type. 10 pregnant women with HIV participated in the focal group. After the dynamics of the focal group, we analyzed the testimonies of the same and built an educational technology containing the main questions of the participants and answers with references of studies conducted by the Ministry of Health. Results: With the methodology performed, it was possible to construct an educational video called "Pregnancy in women with HIV: Let's talk about?" as the final product. Regarding their questioning, it was possible to emphasize that they did not know how to perform selfcare in a correct way and that they present fear in the stigma contained in the disease. Conclusion: The elaboration of educational tools is presented as a way to remedy doubts and presents itself as a way of increasing the bond between the professional and the user.
\end{abstract}

Key words: Pregnant women, Self-care, Education.

\section{RESUMEN}

Objetivo: Construir una tecnología de salud educativa para las mujeres embarazadas seropositivas del HIV. Métodos: Estudio descriptivo, de carácter cualitativo, del tipo de investigación participante. 10 mujeres

1Universidade do Estado do Pará (UEPA), Belém-PA. *E-mail: serraojeanemiranda1@gmail.com 
embarazadas con HIV participaron en el grupo focal. Después de la dinámica del grupo focal, analizamos los testimonios del mismo y construimos una tecnología educativa que contiene las principales preguntas de los participantes y respuestas con referencias de estudios realizados por el Ministerio de Salud. Resultados: Con la metodología realizada, fue posible construir un video educativo llamado "Embarazo en mujeres con VIH: ¿Hablemos de?" como el producto final. En cuanto a su interrogatorio, fue posible destacar que no sabían cómo realizar el autocuidado de una manera correcta y que presentan temor en el estigma contenido en la enfermedad. Conclusión: La elaboración de herramientas educativas se presenta como una forma de subsanar dudas y se presenta como una forma de aumentar el vínculo entre el profesional y el usuario.

Palabras clave: Mujeres embarazadas, Autocuidado, Educación.

\section{INTRODUÇÃO}

O Vírus da Imunodeficiência Humana (HIV) é uma palavra derivada do inglês que significa Human Immunodeficiency Virus. O HIV é o vírus que causa a Síndrome da Imunodeficiência Adquirida (AIDS), sendo considerada assim uma doença que prejudica as defesas do organismo contra infecções e outras doenças (BRASIL, 2014).

A AIDS/HIV positivo pode causar sérios problemas não apenas aos portadores do vírus, mais ao bebê durante a gestação, é sabido que o HIV é uma patologia com muitos agravos, e que se alguns cuidados não forem tomados, a mãe pode transmitir o vírus ao seu bebê, o que se classifica como a transmissão vertical (BRASIL, 2014).

De acordo com o boletim epidemiológico do Ministério da Saúde, Brasil (2018), entre 2000 e 2018 foram notificadas 116.292 gestantes infectadas com HIV. Sendo que 38,6\%\% das gestantes eram residentes da região Sudeste, seguida pelas regiões Sul $(30,4 \%)$, Nordeste $(17,2 \%)$, Norte $(8,0 \%)$ e Centro-Oeste $(5,8 \%)$.

Ressalta-se então que o aumento de casos na população feminina em idade reprodutiva vem como consequência, aumentando ano a ano a frequência de transmissão vertical do HIV, pois algumas mulheres engravidam muitas vezes, sem o conhecimento de que estão infectadas pelo vírus e por desconhecem o perfil sorológico de seus parceiros (COSTA RH, et al., 2015).

Com isso, para Fonseca NS (2015), no cuidado à gestante com HIV, podem surgir diversos conflitos, podendo ser citada a preocupação do risco de contaminação vertical, pelo despreparo em lidar com esse público ou até mesmo pelo estabelecimento do respeito ao direito reprodutivo dessas mulheres. Diante dessa temática, o autocuidado é definido como a adoção de hábitos saudáveis como: alimentação adequada, práticas de atividades físicas, lazer e mudanças no estilo de vida na promoção da saúde e prevenção de agravos (BRASIL, 2004).

O autocuidado pode ser entendido como a prática de atividades exercidas pelo indivíduo visando o seu benefício em busca da manutenção da vida, da saúde e do bem-estar (SOUZA ELV, et al., 2012). Este conceito de autocuidado tem sofrido evolução no decorrer do tempo, estando relacionado à autonomia, independência e responsabilidade individuais para hábitos e comportamento saudáveis, assim como para a elaboração de atividades necessárias para administrar e acompanhar as condições de saúde (CONCEIÇÃO AP, et al., 2015).

Já a educação em saúde pode ser compreendida como um espaço de práticas e de conhecimentos do setor saúde que se ocupa, mais objetivamente, com a efetivação de vínculos entre o campo assistencial e o pensar/fazer na rotina das comunidades e indivíduos. Significa expressar que toda a ação em saúde se constitui como ação educativa, haja vista que inúmeros processos da saúde, como a promoção, prevenção, cura e reabilitação também são práticas e processos pedagógicos (PINHEIRO BC e BITTAR CML, 2016).

Ressalta-se ainda que o processo de Educação Para a Saúde (EPS) deve constituir um processo interativo reconhecido e aceito pela comunidade, a qual deve adquirir uma postura de participação ativa e de parceria com responsabilidades na determinação da sua própria saúde e qualidade de vida (FONSECA NS, 2015). 
Neste contexto, observa-se a importância da elaboração de Tecnologias Educacionais em Saúde (TES) que são entendidas como dispositivos para a intermediação de processos de ensinar e aprender que são usadas entre educadores e educandos, nos mais variados processos de educação. Estas tecnologias podem ser apresentadas em diversas modalidades, tais como: táteis e auditivas, expositivas e dialogais, impressas e audiovisuais (TEIXEIRA E e MOTA VMSS, 2011).

É notória que a utilização de materiais educativos na área da saúde, segundo Reberte LM, et al. (2012), é prática comum no Sistema Único de Saúde (SUS). Manuais de cuidado em saúde, folhetos, cartilhas, dentre outros, são capazes de promover resultados expressivos para os participantes das atividades educativas. A contribuição desses materiais para a promoção da saúde depende dos princípios e das formas de comunicação envolvidos nos processos de elaboração.

A luz dos conceitos supracitados, este estudo tem como objetivo elaborar uma TES sobre o autocuidado para gestantes soropositivas para HIV.

\section{MÉTODOS}

Realizou-se um estudo descritivo, de natureza qualitativa, do tipo pesquisa participante. A pesquisa foi desenvolvida em um centro de referência em HIV/AIDS da rede pública de saúde, situado em Belém-PA, com participação de gestantes que realizam o pré-natal no cenário em questão, em julho de 2019. As mulheres foram convidadas durante a consulta de rotina do pré-natal, por meio de um convite para divulgação do grupo educativo.

O critério de inclusão foi ser gestante com soropositividade para HIV que realiza o pré-natal de forma assídua.

Foram excluídas as mulheres menores de idade e as que não quiseram participar do estudo. A construção da TES se deu a partir dos resultados da conversação realizada dentro do grupo focal. Destaca-se que a técnica de grupo favorece a obtenção de perspectivas diferentes sobre uma mesma questão e torna oportuna a compreensão de ideias coletivas, que são elaboradas a partir da influência que o convívio social proporciona (SILVA SS, 2013).

Para a elaboração da TE, primeiramente foi exibido um vídeo do ministério da saúde com informações à cerca da perspectiva de uma mulher grávida com HIV ter um filho sem o vírus e a importância dos cuidados da gravidez em linhas gerais. Após a exibição do filme foi realizado dinâmica de apresentação para a construção do grupo focal, com intuito de identificar os conhecimentos das mesmas a respeito do que elas idealizavam como sendo o autocuidado e o uso de uma TE que atendesse a realidade das gestantes portadoras do vírus HIV assistidas no centro de referencia em que foi realizada o estudo.

Ressalta-se ainda que a metodologia do grupo focal (GF) apresenta-se como objetivo principal de agrupar informações sobre uma temática específica, por meio de discussão e debate entre os participantes em forma de uma reunião sobre uma temática específica em um período delimitado (KINALSI DDF, et al., 2017).

Após isso, foi realizada a organização das discussões e sistematização do conteúdo a ser explanado na TE, de acordo com o protocolo e recomendações do pré-natal do Ministério da Saúde. Por fim, foi construído o tipo de tecnologia sugerida pelas gestantes.

No que se refere ao conteúdo da TES, os fatores que o determinaram foram as informações obtidas por meio do GF com as gestantes concomitantemente aos critérios estabelecidos pelos órgãos afins e o que é preconizado pelo Ministério da Saúde.

A pesquisa atendeu aos preceitos éticos da Resolução n. 466/2012 do Conselho Nacional de Saúde. Foi aprovada no Comitê de Ética em Pesquisa da Universidade do Estado do Pará, sob no do parecer: 3.401.472. Todas as participantes assinaram o Termo de Consentimento Livre e Esclarecido, e o sigilo de suas identidades foi assegurado utilizando-se código alfanumérico para identificação com a letra G, de Gestantes, e número de ordem das entrevistas. 


\section{RESULTADOS}

Participaram do estudo 10 gestantes, predominando a faixa etária de 22 a 26 anos, com cinco (50\%) participantes. Além disso, seis $(60 \%)$ estavam em sua segunda gestação. Em relação ao tempo de diagnóstico de HIV, a média de idade foi de quatro anos (mínimo menos de 10 meses e máximo de 14 anos). Todas afirmaram realizar da terapia antirretroviral de forma rotineira.

Tabela 1 - Perfil social das gestantes participantes da pesquisa.

\begin{tabular}{|c|c|c|c|c|c|}
\hline GESTANTE & IDADE & GESTAÇÃO & $\begin{array}{l}\text { ESTADO } \\
\text { CIVIL }\end{array}$ & $\begin{array}{c}\text { TEMPO DE } \\
\text { DIAGNÓSTICO }\end{array}$ & $\begin{array}{c}\text { TERAPIA } \\
\text { ANTIRRETROVIRAL }\end{array}$ \\
\hline G1 & $\begin{array}{c}18 \text { a } 22 \\
\text { anos }\end{array}$ & Primeira & Solteira & 10 meses & Faz uso diariamente \\
\hline G2 & $\begin{array}{l}22 \text { a } 26 \\
\text { anos }\end{array}$ & Segunda & Solteira & 36 meses & Faz uso diariamente \\
\hline G3 & $\begin{array}{l}22 \text { a } 26 \\
\text { anos }\end{array}$ & Segunda & Casada & 11 meses & Faz uso diariamente \\
\hline G4 & $\begin{array}{c}\text { Acima } \\
\text { de } 36 \\
\text { anos }\end{array}$ & Primeira & Casada & 168 meses & Faz uso diariamente \\
\hline G5 & $\begin{array}{c}30 \text { a } 36 \\
\text { anos }\end{array}$ & Terceira & Casada & 84 meses & Faz uso diariamente \\
\hline G6 & $\begin{array}{l}22 \text { a } 26 \\
\text { anos }\end{array}$ & Segunda & $\begin{array}{l}\text { Relação } \\
\text { estável }\end{array}$ & 24 meses & Faz uso diariamente \\
\hline G7 & $\begin{array}{c}22 \text { a } 26 \\
\text { anos }\end{array}$ & Segunda & $\begin{array}{l}\text { Relação } \\
\text { estável }\end{array}$ & 10 meses & Faz uso diariamente \\
\hline G8 & $\begin{array}{c}\text { Acima } \\
\text { de } 36 \\
\text { anos }\end{array}$ & Segunda & $\begin{array}{l}\text { Relação } \\
\text { estável }\end{array}$ & 60 meses & Faz uso diariamente \\
\hline G9 & $\begin{array}{c}26 \text { a } 30 \\
\text { anos }\end{array}$ & Segunda & $\begin{array}{l}\text { Relação } \\
\text { estável }\end{array}$ & 24 meses & Faz uso diariamente \\
\hline G10 & $\begin{array}{c}26 \text { a } 30 \\
\text { anos }\end{array}$ & Primeira & $\begin{array}{l}\text { Relação } \\
\text { estável }\end{array}$ & 48 meses & Faz uso diariamente \\
\hline
\end{tabular}

Fonte: Serrão JRM, et al., 2019.

Mediante ao conteúdo analisado, foi possível observar quais práticas de autocuidado as participantes realizam e, a partir disso, construir uma TES para auxiliar as mesmas na realização dessas.

Primeiramente, quando questionadas sobre quais seriam as dúvidas mais recorrentes delas a respeito de sua gestação, foi destacado por sete $(70 \%)$ gestantes o não conhecimento sobre como realizar o autocuidado durante a gestação.

"Eu ainda sei muito pouco... Não sei falar." (G4)

"A gente tem que saber o que pode ou não comer e beber, no começo eu tomava muitas latinhas de cervejinha, mas percebia que eu ficava fraca, me sentia mal, agora bebo só um copinho de vez em quando, porque sei que faz mal." (G6)

Nesse tema, cinco (50\%) participantes alegaram sobre a importância de saber como expressar a respeito da necessidade do apoio familiar durante o pré-natal e puerpério.

"Primeiro deveria ter mais apoio da família né? Então também ensinar pra família sobre HIV." (G1)

"É muito difícil pra mim, mas tenho que encarar e informar a minha família também pra eles me ajudarem, não sei como fazer." (G9) 
Destaca-se nos depoimentos também que oito (80\%) das grávidas apresentavam como dúvidas como realizar o enfrentamento com a sociedade a respeito da gravidez e a soropositividade para HIV.

"Tem casos [de gestantes com soropositividade para HIV] diferentes né? Uns [já são] indetectáveis e aqueles que estão começando agora. 'Ah porque neles a carga é indetectável eu posso diminuir aquela pessoa que chegou agora....' Então eu acho isso um tipo de preconceito, e isso afeta muito que deixa cabisbaixa né? Oprimida pode sumir e acaba não se cuidando..." (G2)

"É muito importante falar, ensinar pra gente a forma como dar desculpa para as pessoas sobre porque não ter filho de parto normal, não amamentar ao seio, porque fazer o pré-natal fora da nossa cidade (sou do interior né), lá até a minha família quer saber, e eu não conto pra todos que sou soro positivo né. As vezes acabo não fazendo tudo [o pré-natal] com vergonha de ter que explicar para as pessoas." (G4)

"Já é o meu $2^{\circ}$ filho, né? Já sei muita coisa né? O que faz mal ou não, que não devo beber, me alimentar bem, não vou poder dar de mamar, talvez não tenha filho de parto normal... Muitas coisas, mas acho que principalmente é bom a gente aprender a se defender das pessoas que vivem querendo saber porque isso e aquilo..." (G8)

Quando indagadas sobre qual tipo de tecnologia educacional deveria ser construído no final do estudo, todas $(100 \%)$ as participantes pontuaram a elaboração de um vídeo educacional contendo as respostas para os questionamentos mais recorrentes pelas grávidas.

"O vídeo é melhor dá mais vontade de assistir do que de ler." (G1)

"No vídeo temos a oportunidade de tirar dúvidas de forma segura e com bastante informações." (G2)

"O vídeo é mais interessante ele proporciona estímulos, convence melhor, sem dúvida." (G7)

Culminou-se, então, como produto, um vídeo educativo, a qual se construiu ao longo de um processo que envolveu fases bem definidas, desde a adequada formulação do problema até a satisfatória apresentação dos resultados. Intitulou-se o vídeo de "A gravidez em mulheres com HIV: vamos falar sobre?", em forma de perguntas e respostas por meio de frases objetivas e imagens coloridas para ser mais atrativo para as leitoras.

Imagem 1 - Tecnologia educacional em forma de vídeo.

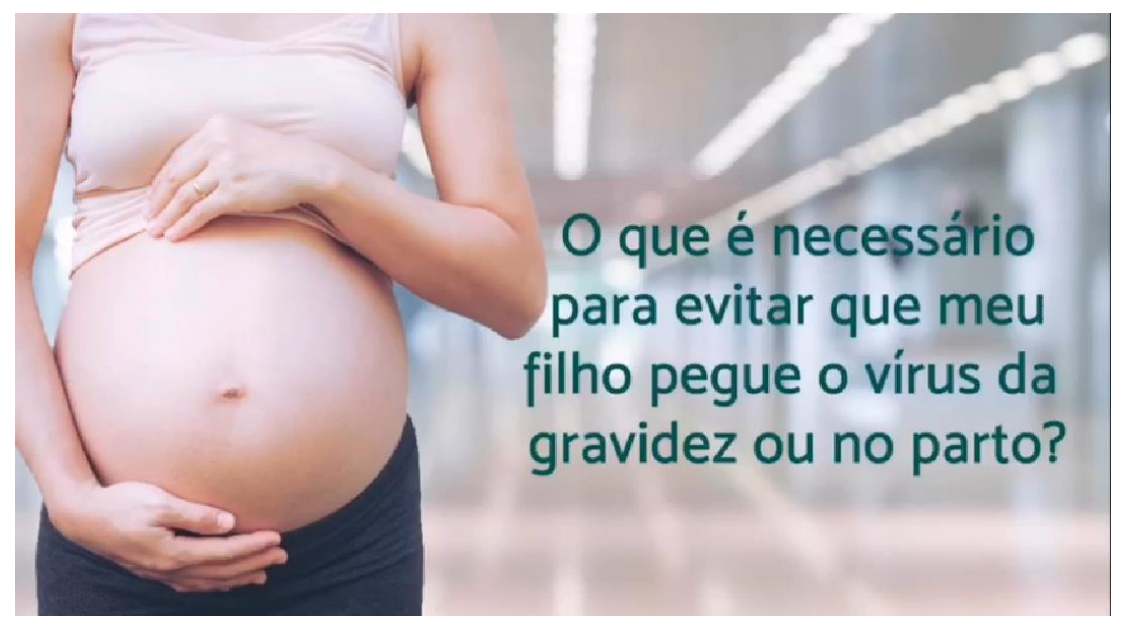

Fonte: Serrão JRM, et al., 2019.

Com relação ao conteúdo contido no vídeo, foram pontuados os principais questionamentos realizados pelas gestantes durante a roda de conversação, no qual foi possível destacar a importância da realização do pré-natal e as medidas de autocuidado primordiais para a não transmissão vertical. Além desses pontos, foi abordado no vídeo sobre a importância da aceitação e do enfretamento da doença para a melhoria da qualidade de vida. 
Ressalta-se ainda para a construção da TES, foi utilizada linguagem objetiva e de fácil entendimento, no qual foram utilizadas fontes grandes e textos curtos distribuídos entre imagens, tornando o material mais didático.

\section{DISCUSSÃO}

O autocuidado no ciclo gravídico-puerperal, segundo Rahim SH et al. (2017), apresenta-se como sendo um dos enfoques em condutas de linhas de cuidado à saúde da mulher dentro das políticas de saúde brasileiras. Nessa conjuntura, a assistência ao pré-natal é de extrema importância, sobretudo para mulheres em condições crônicas de saúde, como no contexto do HIV.

Destaca-se ainda que as orientações de autocuidado para o período gestacional devem ser iniciadas durante as primeiras consultas de pré-natal e, se possível, ser reafirmada por meio de grupos educativos entre gestantes e também em sala de espera (SILVA SR, et al., 2014)

Estudos de Rubiano YLM, et al. (2016) destaca que o desejo das gestantes de terem os seus filhos sem o vírus e que elas possam criá-los e educá-los, fazem com que as mesmas tenham um maior incentivo de realizar com eficácia o tratamento para o HIV. Isto é, o principal motivo para a manutenção e para a realização correta do tratamento durante a gestação é que elas passam a perceber o filho como extensão de si próprio e, com isso, necessitarão estar saudáveis para realizar os cuidados necessários relacionados à maternidade.

Com isso, observa-se a importância do uso da terapia antirretroviral durante todo o período gravídico, visto que se trata de uma forma de prevenir a transmissão vertical do HIV e possibilitar a boa qualidade de vida para a gestante (FARIA ER, 2014).

Ressalta-se também que o uso de bebidas alcoólicas na gestação influencia negativamente na condição de saúde e, quando destacada as mulheres com HIV, o uso do mesmo prejudica na adesão ao tratamento, além de aumentar o risco de transmissão do vírus e de relações sexuais desprotegidas (SANTOS VF, et al., 2017).

O autocuidado no ciclo gravídico-puerperal, segundo Rahim SH, et al. (2017), apresenta-se como sendo um dos enfoques em condutas de linhas de cuidado à saúde da mulher dentro das políticas de saúde brasileiras. Nessa conjuntura, a assistência ao pré-natal é de extrema importância, sobretudo para mulheres em condições crônicas de saúde, como no contexto do HIV.

Um estudo realizado por Silva SR, et al. (2014) evidência que práticas de autocuidado desenvolvidas pelas gestantes que não apresentam soropositividade para o HIV rodeiam principalmente a questão alimentar, sendo citada pelas participantes da pesquisa a importância de realizar uma alimentação balanceada para garantir uma boa gestação.

Quando então aliamos a gravidez à infecção pelo HIV, essa gestante apresenta consigo uma maior responsabilidade de desenvolver o autocuidado e, nesse contexto, a figura do profissional da saúde, podendo aqui se destacar do papel da enfermagem, apresenta-se de forma primordial, pois é ele quem fornecerá orientações para o autocuidado dessa mãe, de modo a promover a manutenção da integridade estrutural e do funcionamento humano, situações essas que contribuem para o desenvolvimento e recuperação da saúde (BARROSO LMM, et al., 2010).

Observa-se que existem fatores que contribuem no engajamento do autocuidado, como por exemplo, o estabelecimento da rede de apoio familiar e social, pois quando a família sabe e apoia a gestante/puérpera com HIV, essa vivência passa a ser menos sofrida. Um estudo realizado em 2009 destacou que essa rede serve para dar conselhos e esclarecer dúvidas, provavelmente em função de experiências vividas; relatam ainda que encontram suporte fora do âmbito familiar com as amigas, vizinhas, patroa, colegas de trabalho e outras gestantes (SCHERER LM, et al., 2009).

Reflete-se ainda que as intercorrências no período gravídico-puerperal podem fragilizar a mulher e sua família e conduzir, muitas vezes, ao ápice do sofrimento psíquico. E a oferta do apoio psicológico nesse 
cenário pode beneficiar à gestante na elaboração e reflexão sobre quais melhores estratégias de enfrentamento diante de sua condição clínica (VANESSA KSL, et al., 2019).

Estudos de Silva SS et al. (2015) afirma que o estigma da doença é um dos principais e mais preponderantes fatores que influenciam na capacidade da mulher em aderir ao tratamento do HIV e seguir as recomendações dos programas de controle da transmissão vertical (TV).

As mulheres grávidas com HIV apresentam receios sobre o preconceito gerado em torno da doença e isso traz como consequência a dificuldade na adesão na prevenção da TV. Silva et al. (2015) ainda ressalta que o medo da discriminação, do abuso e a negação de serviços de saúde fazem com que as gestantes apresentem entrave na hora da realização do teste de HIV.

Diante disso, percebe-se a importância de desenvolver uma assistência individual e singular às mulheres grávidas com HIV e a utilização de ferramentas educacionais é observada como forma de auxiliar o processo de auxílio para essas participantes sobre a realização do autocuidado.

Visto isso, ressalta-se que a construção da TES foi desafiadora, visto que o tema traz consigo muitos estigmas e as próprias participantes apresentaram medo de se expressar sobre como as mesmas se sentiam perante a temática proposta.

Destaca-se ainda que a formação do grupo proporcionou uma melhor aproximação entre as grávidas soropositivas para HIV o que se espera que isso ajude na melhor troca de experiências entre elas, pela cumplicidade entre pares e fortalecimento do grupo que por diversos relatos sentem-se discriminadas pela sociedade.

\section{CONCLUSÃO}

Com o estudo, pode-se constatar que as participantes apresentam diversas dúvidas a respeito do tema estudado, além de apresentar medo em expressar os mesmos. Com isso, é destacada a importância de elaboração de tecnologias educacionais que apresentem como objetivo o maior entendimento entre profissionais e usuários, realizando assim, em uma visão integradora das dimensões da vida das pessoas e a construção e efetivação de vínculos dentro do setor saúde entre o educador e o educando.

\section{REFERÊNCIAS}

1. BARROSO LMM, et al. Utilidade da teoria de autocuidado na assistência ao portador do Vírus da Imunodeficiência Humana/ Síndrome da Imunodeficiência Adquirida. Acta Paul. Enferm, 2010; 23(4): 562-567.

2. BRASIL. Ministério da Saúde. Política Nacional de Atenção Integral à Saúde da Mulher. Princípios e Diretrizes. Brasília; 2004. 82 p.

3. BRASIL. Ministério da Saúde. Manual Técnico Para o Diagnóstico da Infecção Pelo HIV. Brasília: Ministério da Saúde, 2014. 140 p.

4. BRASIL. Ministério da Saúde. Boletim epidemiológico Aids e DST. Brasília: Ministério da Saúde; 2018. 72 p.

5. CONCEIÇÃO AP, et al. Autocuidado de Pacientes com Insuficiência Cardíaca. Rev. Latino-Am Enfermagem, 2015; 23(4): 578-86.

6. COSTA RH, SILVA RA, MEDEIROS SM. Nursing Care Across The Prevention of Vertical Transmission of HIV.J Res Fundam Care. 2015; 7(1):2147-58.

7. FARIA ER. Gestação e HIV: preditores da adesão ao tratamento no contexto do pré-natal. Psic: Teor Pesq. 2014; 30(2): 197-203.

8. FONSECA NS. Assistência de Enfermagem às Gestantes com VIH. Trabalho de Conclusão de Curso (Licenciatura em Enfermagem). Universidade do Mindelo. Mindelo, 2015; 85p.

9. KINALSKI DDF, et al. Grupo focal na pesquisa qualitativa: relato de experiência. Rev Bras Enferm, 2017; 70(2):4438. 
10. PINHEIRO BC, BITTAR CML. Práticas de Educação Popular em Saúde na Atenção Primária: uma revisão integrativa. Cinergis, 2016; 8(1): 77-82.

11. RAHIM SH, et al. Gestantes e puérperas soropositivas para o HIV e suas interfaces de cuidado. Rev enferm UFPE on line, 2017; 11(10):4056-64.

12. REBERTE LM, et al. O Processo de Construção de Material Educativo para a Promoção da Saúde da Gestante. Rev. Latino-Americana de Enferm, 2012. 20(1): 101-108.

13. RUBIANO YLM, et al. Más allá de mí: cuidarme para proteger mi hijo. Experiencias de mujeres gestantes con VIH/SIDA. RevUnivind Santander Salud, 2016; 48(3): 353-363.

14. SANTOS VF, et al. Efeito do álcool em pessoas com HIV: tratamento e qualidade de vida. Acta Paul Enferm, 2017; 30(1):94-100.

15. SCHERER LM, et al. Gestantes/puérperas com HIV/AIDS: conhecendo os déficits e os fatores que contribuem no engajamento para o autocuidado. Esc Anna Nery Ver Enferm, 2009; 13(2): 359-65.

16. SILVA LHF, SANTO FHE. Tecnologia educacional interativa como estratégia de educação permanente: um estudo descritivo. Online Brazilian Journal of Nursing, 2013; 12(1): 701-703

17. SILVA SR. et al. Práticas de autocuidado desenvolvidas por gestantes atendidas em um ambulatório de pré-natal. Rev. Eletr. Enf., 2014;16(4):812-21.

18. SILVA SS, et al. Rede de apoio a mulheres com HIV na prevenção da transmissão vertical: revisão integrative. Rev Min Enferm,2015; 19(2): 225-231.

19. SOARES LQ, FERREIRA MC. Pesquisa participante como opção metodológica para investigação de práticas de assédio moral no trabalho. Rev. Psicol., Organ. Trab., 2006; 6(2): 85-109.

20. SOUZA ELV, et al. Diagnósticos de Enfermagem Embasados na Teoria do Autocuidado em Pessoas com Deficiência Visual. Reve Rene, 2012; 13(3): 542-551.

21. TEIXEIRA E, MOTA VMSS. Tecnologias educacionais em foco. 1.ed. São Caetano do Sul: Difusão, 2011.

22. VANESSA KSL, et al. Educação em saúde para gestantes: a busca pelo empoderamento materno no ciclo gravídicopuerperal. Rev. fundam. care. online, 2019; 11(4): 968-975. 